Int. J. Electrochem. Sci., 13 (2018) $6218-6228$

International Journal of

ELECTROCHEMICAL

SCIENCE

www.electrochemsci.org

\title{
Novel Electrochemical Sensor for Highly Sensitive Detection of Adenine Based on Vanadium Pentoxide Nanofibers Modified Screen Printed Carbon Electrode
}

Muthaiah Annalakshmi ${ }^{1}$, Arumugam Sangili, Shen-Ming Chen ${ }^{1, *}$, Tse-Wei Chen ${ }^{1}$, Xiaoheng Liu $^{2, *}$, V. Selvam ${ }^{3}$,

${ }^{1}$ Electroanalysis and Bioelectrochemistry Lab, Department of Chemical Engineering and

Biotechnology, National Taipei University of Technology, No. 1, Section 3, Chung-Hsiao East Road, Taipei 106, Taiwan, ROC.

${ }^{2}$ Key Laboratory of Education Ministry for Soft Chemistry and Functional Materials, Nanjing University of Science and Technology, Nanjing 210094, China.

${ }^{3}$ M.D.T. Hindu College Pettai, Tirunelveli 627010, Tamilnadu, India.

*E-mail: smchen78@ms15.hinet.net, xhliu@mail.njust.edu.cn

doi: $10.20964 / 2018.07 .41$

Received: 24 March 2018 / Accepted: 6 May 2018 / Published: 5 June 2018

Herein, we report a simplistic approach to prepare vanadium pentoxide nanofibers $\left(\mathrm{V}_{2} \mathrm{O}_{5} \mathrm{NFs}\right)$ using simple hydrothermal method. The as-synthesized material was confirmed by X-ray diffraction (XRD), energy dispersive X-ray spectroscopy (EDX) techniques, scanning electron microscopy (SEM). In addition, $\mathrm{V}_{2} \mathrm{O}_{5}$ NFs was used as an electrocatalytic performance towards the electro-oxidation of Adenine. Interestingly, $\mathrm{V}_{2} \mathrm{O}_{5}$ NFs modified electrode $\left(\mathrm{V}_{2} \mathrm{O}_{5}\right.$ NFs/SPCE $)$ showed an excellent electrocatalytic activity towards Adenine with lower detection limit $(0.013 \mu \mathrm{M})$, wide linear ranges $(0.5$ to $512 \mu \mathrm{M})$ and the higher sensitivity about $8.5333 \mu \mathrm{A} \mu \mathrm{M}^{-1} \mathrm{~cm}^{-2}$. Furthermore, $\mathrm{V}_{2} \mathrm{O}_{5} \mathrm{NFs} / \mathrm{SPCE}$ was also demonstrated good recovery even in real human urine samples. This study opens a new window for the trace level identification of biological molecules in real samples.

Keywords: Vanadium pentoxide, nano-fibers, Adenine, electro-oxidation, human urine sample.

\section{$\underline{\text { FULL TEXT }}$}

(C) 2018 The Authors. Published by ESG (www.electrochemsci.org). This article is an open access article distributed under the terms and conditions of the Creative Commons Attribution license (http://creativecommons.org/licenses/by/4.0/). 